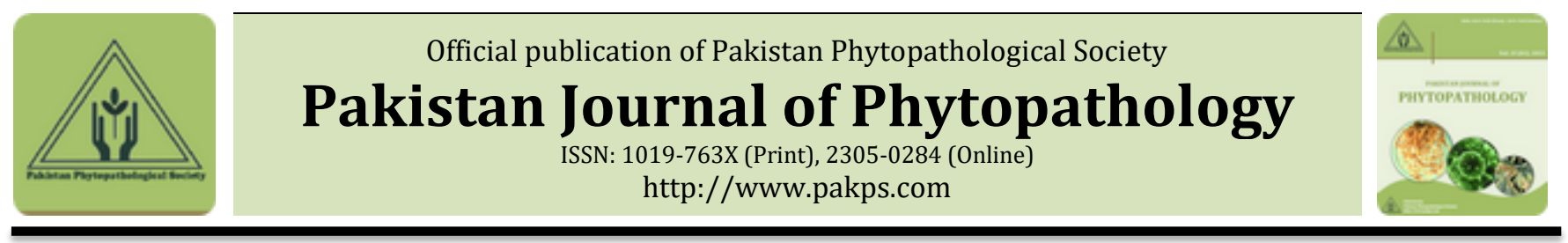

\title{
SUSCEPTIBILITY OF CHILLI LINES / VARIETIES TOWARDS CHILLI LEAF CURL VIRUS AND ITS MANAGEMENT THROUGH VECTOR CONTROL
}

\author{
Muhammad S. Hussain, Khalid Naveed*, Muhammad Atiq \\ Department of Plant Pathology, University of Agriculture, Faisalabad, Pakistan.
}

\section{A B S T R A C T}

Chilli leaf curl virus (ChiLCV) is a serious problem for chilli production in Pakistan and India. In this study, fourteen different chilli lines / varieties were screened for their resistance/susceptibility towards ChiLCV in open field trials. Data of disease severity and disease incidence was recorded on weekly basis. Out of all varieties screened, Tatapuri Chilli and CH111 showed high susceptibility towards the chilli leaf curl disease. Talhari, CH 99, CH103, CH 106, CH107, CH108, CH109, GSL111 showed susceptible response whereas CBS1292 showed moderately susceptible response towards the disease. Only two cultivars Hybrid-46 and Hot Queen were found as moderately resistant. The screening experiment showed that most of the chilli varieties are susceptible to chilli leaf curl disease and resistance is lacking in local germplasm. Furthermore, three insecticides: Imidacloprid, Polo and Emamectin were tested for their efficacy for the management of disease and whitefly vector in field conditions at weekly intervals. Out of three insecticides, Polo gave best results as compared to Emamectin and Imidacloprid against chilli leaf curl disease and whitefly vector.

Keywords: Chilli leaf curl virus, insecticides, disease severity, whitefly, management

\section{INTRODUCTION}

Chilli (Capsicum annum L.), also known as pepper, is a vegetable crop from the genus Capsicum and family Solanaceae (Olmstead et al., 2008). Chilli has its origin from Mexico where it was cultivated around 6000 years ago and was brought to Asia during the $16^{\text {th }}$ century by Portuguese navigators (Bosland and Votava, 2000; Kraft et al., 2014). The intensity and pungency of chilli pepper is due to a naturally occurring compound capsaicin and other chemicals collectively known as capsaicinoids (Dorantes et al., 2000). It is commonly grown in several subtropical and tropical countries and is used in both food and medicine. It is commercially grown in Pakistan in all four provinces (Iqbal et al., 2012). In Pakistan, chilli was grown on 171,800 hectares of land with a total production of 463,860 tons during the year 2011. Sindh is the major chilli producing province followed by Punjab, Baluchistan and Khyber Pahtunkhwa (Pakistan Bureau of Statistics, 2010-11). India is a major chilli

* Corresponding Author:

Email: khalid.naveed@uaf.edu.pk

(C) 2017 Pak. J. Phytopathol. All rights reserved. growing country and second largest export in the international market that exports chilli across 90 different countries. It exports different products of chilli including chilli powder, dried chilli and oleoresins (Peter, 1999).

Chilli is used for different household uses as spice and vegetable, pickling and in sauce making (Kumar and Rai, 2005a). It has uses as oleoresin and for other spiritual purposes (Kumar et al., 2006b; Meghvansi et al., 2010). Chilli contains vitamin A, C, $\beta$-carotene, potassium, and several other antioxidants which offer numerous health benefits. Consumption of chilli protects against the risk of cancer and diabetes (Pawar et al., 2011). The crop is infected by several fungi, bacteria, viruses and nematodes which cause severe yield losses. Among the numerous factors, diseases caused by plant viruses are a significant factor. Several viruses infect chilli crop which result in significant yield losses in chilli crop each year (Hameed et al., 1995).

ChiLCV (genus Begomovirus; family Geminiviridae) has circular single-stranded DNA genome with associated betasatellites (Fauquet and Stanley, 2003). Whitefly, 
Bemisia tabaci transmits ChiLCV in persistent-circulative manner in nature. Main symptoms of disease include vein clearing, curling and puckering of leaves. Infected plants are stunted and remain smaller in size. Flower buds abscise before reaching full size with little or no fruit formation and smaller sized fruits (Senanayake et al., 2006a; 2012b). In case of severe infections, crop losses may reach up to $100 \%$ resulting in total crop failure (Kumar et al., 2006b). The disease has been reported from many countries including India, United States of America, Nigeria, Bangladesh and Indonesia (Stenger et al., 1990; Fauquet and Stanley, 2003)

ChiLCV can be controlled by managing its vector $B$. tabaci, through resistant germplasm and by adopting other disease management strategies. Resistant germplasm provides long-term and ecofriendly control of viral diseases of plants (Gomez et al., 2009).
Identification of resistant source against pathogen is very crucial for disease management. For this purpose, screening of available chilli lines / varieties was done to find out resistant germplasm.

\section{MATERIALS AND METHODS}

Plant Materials: Fourteen different chilli lines / varieties were raised during the summer season of 2015. No insecticides were applied to protect whitefly population during the experiment. Varieties were screened on the basis of symptoms observation from plants at weekly intervals throughout the season (Fig. 1). Data obtained of symptom severity from each genotype was rated according to the disease rating scale (Kumar et al., 2006b). Disease incidence (DI) was calculated by counting total number of plants and through dividing with population of diseased plants. RCBD layout was used and each line/variety was replicated thrice.

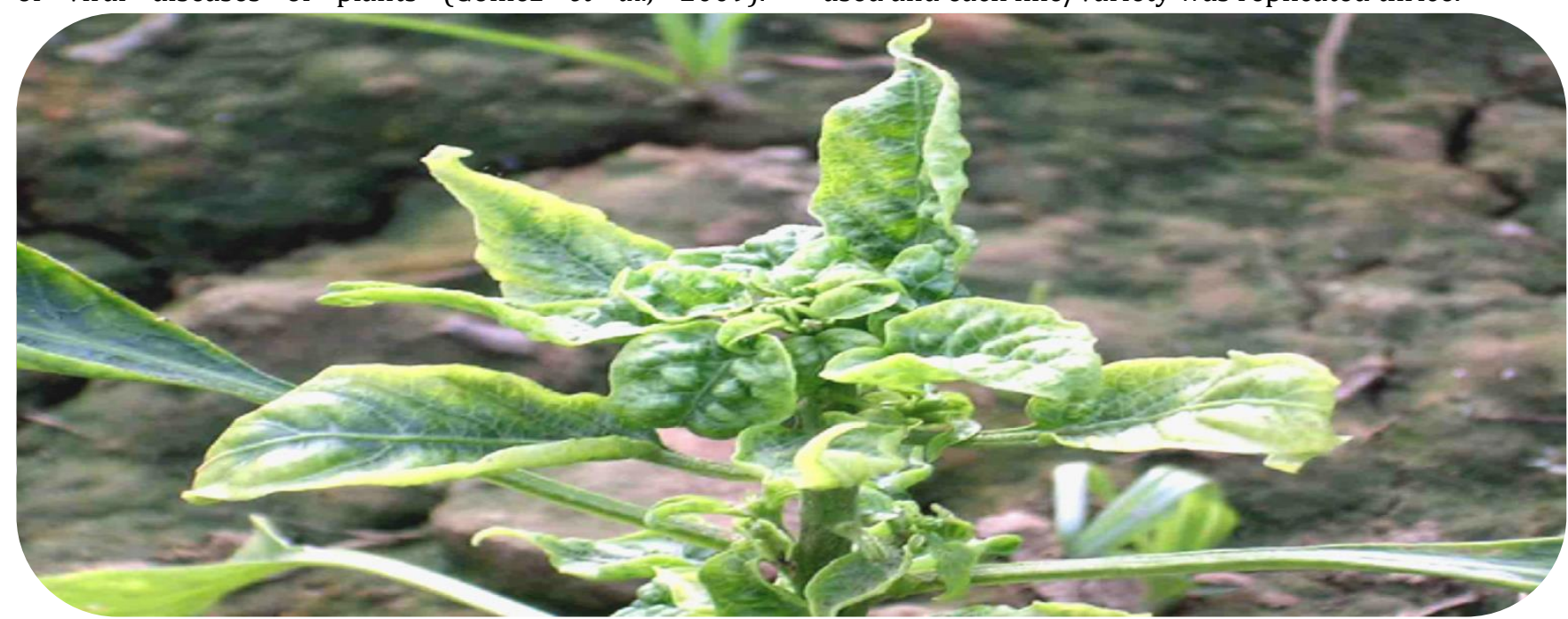

Figure 1. Chilli plant infected with ChiLCV showing typical symptoms of leaf curling, leaf puckering and yellowing.

Disease severity data: Disease severity and disease incidence data were recorded at weekly intervals throughout the season after transplanting by using disease rating scale described by Kumar et al., (2006b): $0 \%$ indicates no symptoms (immune); 1 - $5 \%$ clearing and curling of upper leaves- (highly resistant, HR); 6$25 \%$ curling of leaves and vein swelling-(resistant, R); 26-50\% puckering, leaf curling, yellowing and vein swelling (moderately susceptible, MS); 51-75\% curling of leaves, stunted growth and blistering of internodes(susceptible, S); greater than $75 \%$ leaf curling, deformed leaves, stunted growth with small flowers and little fruit set-(highly susceptible, HS). After fifty days, a disease severity grade was given to each genotype. Data of percentage leaf curling taken at weekly intervals was used for studying disease progression in different genotypes. Whitefly population was calculated early in the morning by using magnifying lens and suction pump. Population was calculated in upper, lower and middle part of individual plant randomly. Pathogenicity of ChiLCV was confirmed through grafting of ChiLCV infected chilli scions onto healthy chilli and datura plants.

In Vivo evaluation of insecticides against Chilli leaf curl disease and whitefly population: Three insecticides (Polo (a.i.diafenthiuron), Imidacloprid and Emamectin) were evaluated for their efficacy against chilli leaf curl disease and whitefly population control. Insecticides were prepared at standard dose (Polo: 200 $\mathrm{ml} / 100$ litres of water; Emamectin $200 \mathrm{ml} / 100$ litres 
of water; Imidacloprid $250 \mathrm{ml} / 100$ litres of water per acre) and sprayed at weakly intervals to find out most suitable whitefly population control under field conditions. Whitefly population and disease severity data were taken before each spray and one day after each spray. Four treatments were maintained including control and three sprays were done at weekly intervals. A set of control plants was maintained in which no insecticides were sprayed in order to evaluate the efficacy of insecticides.

\section{RESULTS AND DISCUSSION}

Results showed that Tatapuri chilli (75.5) and CH111 (71) were found highly susceptible (HS) towards ChiLCV. Talhari Chilli (62.5), CH99 (68), CH103 (63), CH106 (55), CH107 (60), CH108 (53), CH109 (57), GSL111 (45.5) were found susceptible (S) whereas CBS1292 (38) and Anaheim (25.5) showed moderately susceptible (MS) response. Hybrid-46 (19.5) and Hot Queen (16) were found as moderately resistant (MR) (Fig2; Table 1). Screening results indicated that there was no completely immune or resistant variety against ChiLCV. Most of the varieties were severely infected by ChiLCV and they can spread virus to other plants. Kumar et al. (2006b) screened three hundred and seven genotypes against ChiLCV. Varieties were selected into resistant and susceptible under field trials on the basis of co-efficient of infection (CI). Selfed progenies of symptomless and highly resistant lines were infected by viruliferous whiteflies in glasshouse. In trails conducted in glasshouse, three lines; BS-35, GKC-29, and EC497636 did not produce any symptoms of disease. The results were similar to the findings of Shah and Khalid (2001) who screened eleven chilli lines (CV-1, CV-2, CV3, CV-4, CV-5, CV-6, CV-7, CV-10, CV-11, CV-12 and CV21) for resistance towards Chilli veinal mottle virus (CVMV). Out of twelve lines evaluated, CV-1, CV-2, CV-3, CV-7, CV-11 and CV-12did not show any disease symptoms and were not infected as tested through ELISA. The lines CV-5, CV-6, CV-10 and CV-21 showed different reaction i.e., 5, 13, 16, $22 \%$ infection with CVMV respectively. CV-8 showed much severe symptoms and considerably high virus titre $(>2)$. The results of the present study were similar to those reported by Ashfaq et al., (2007) who screened 87 genotypes of urdbean against Urdbean leaf crinkle virus during spring and summer seasons of 2005-06. Out of several genotypes, 9 genotypes were found as highly resistant, 19 genotypes resistant and 29 were found as moderately resistant. 11-19 genotypes were found susceptible and 4-6 as highly susceptible.

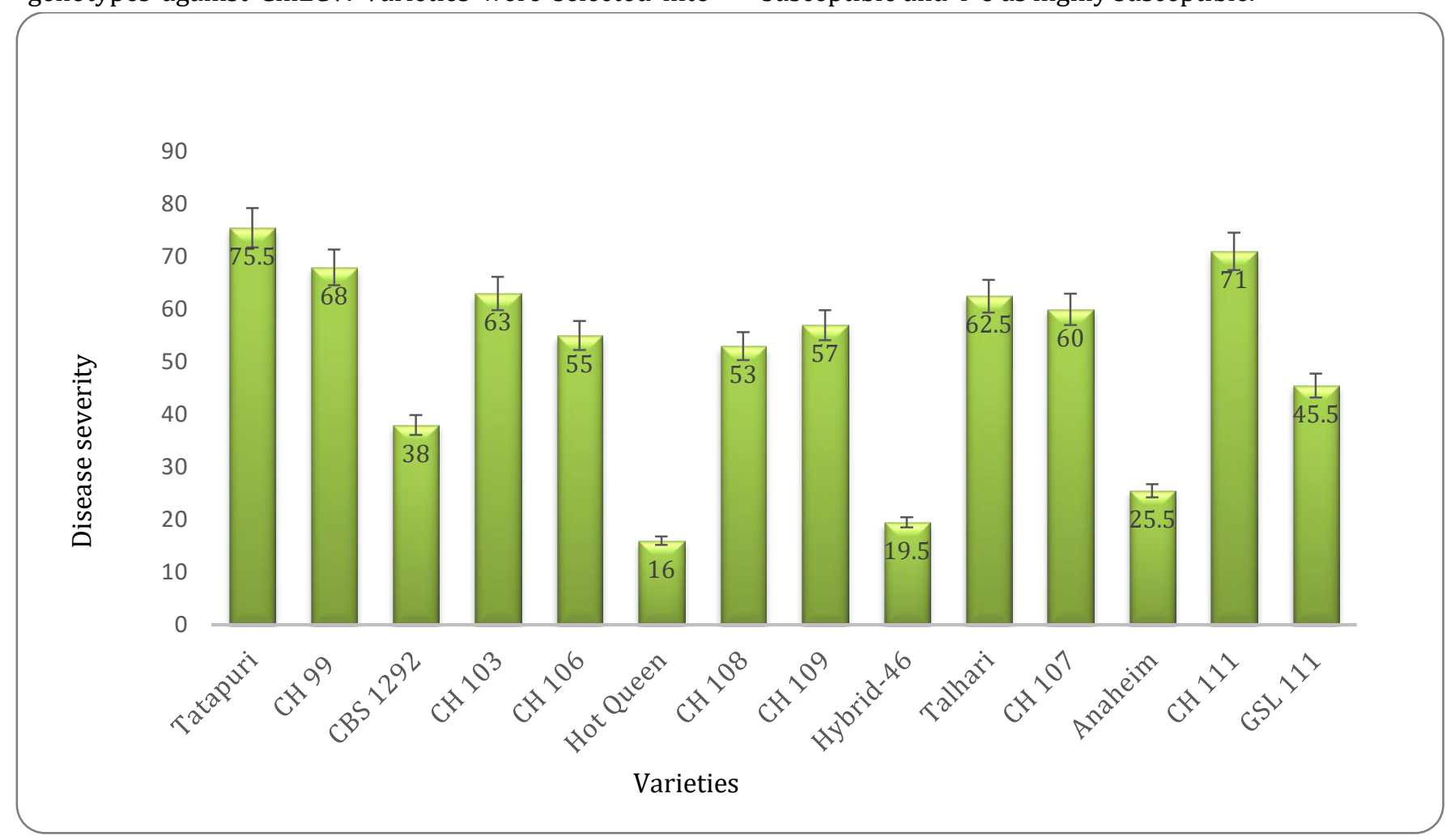

Figure 2. Reaction of chilli varieties against ChiLCV under open field conditions. 
Pak. J. Phytopathol., Vol. 29 (01) 2017. 17-22

Table 1. Level of resistance / susceptibility to ChiLCV exhibited by various chilli lines/varieties

\begin{tabular}{llll}
\hline Varieties & \multicolumn{2}{l}{ Coefficient of Infection } & Disease Reaction \\
\hline CH103 & 63 & B & Susceptible (S) \\
Hybrid-46 & 19.5 & E & Moderately resistant (MR) \\
CBS1292 & 38 & D & Moderately susceptible (MS) \\
Talhari & 62.5 & B & Susceptible (S) \\
Tatapuri & 75.5 & A & Highly Susceptible (HS) \\
GSL111 & 45.5 & B & Susceptible (S) \\
CH99 & 68 & B & Susceptible (S) \\
Hot Queen & 16 & $E^{*}$ & Moderately Resistant (MR) \\
Anaheim & 25.5 & D & Moderately susceptible (MS) \\
CH 111 & 71 & A & Highly Susceptible (HS) \\
CH 106 & 55 & B & Susceptible (S) \\
CH 107 & 60 & B & Susceptible (S) \\
CH 108 & 53 & B & Susceptible (S) \\
CH 109 & B & Susceptible (S) \\
\hline
\end{tabular}

${ }^{*}$ Means sharing common letters do not differ significantly at $p=0.05$

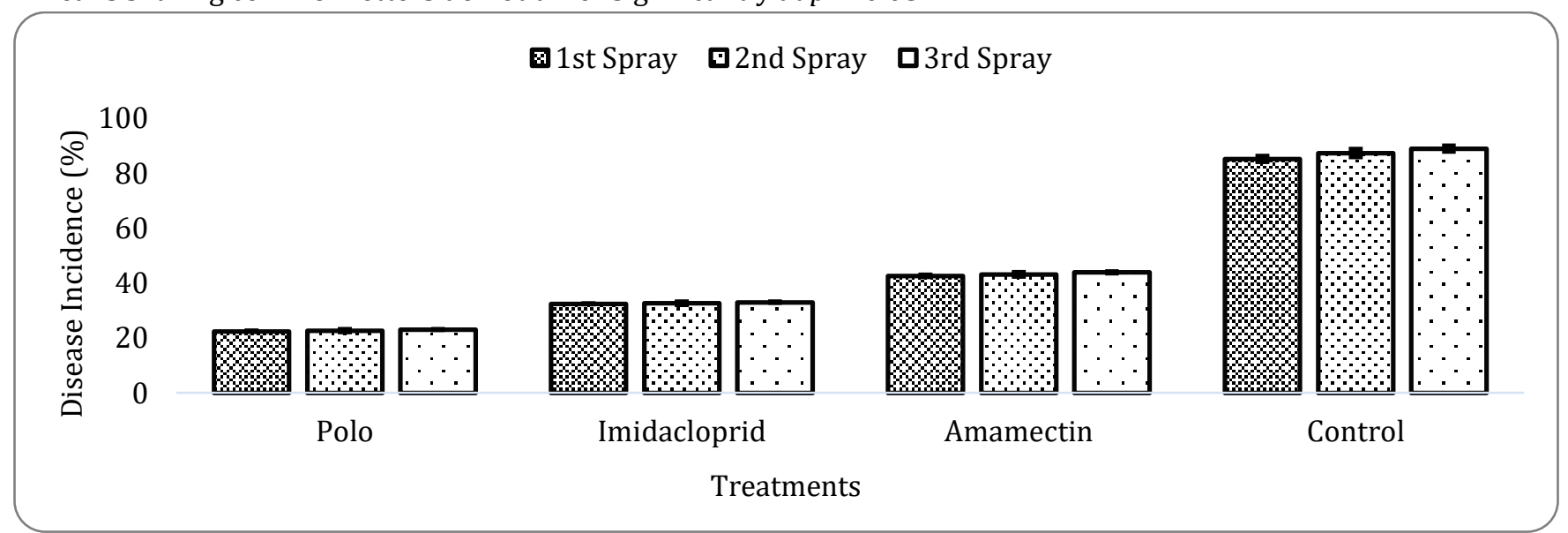

Figure 3. Efficacy of different insecticides for the management of chilli leaf curl disease at four different spray intervals.

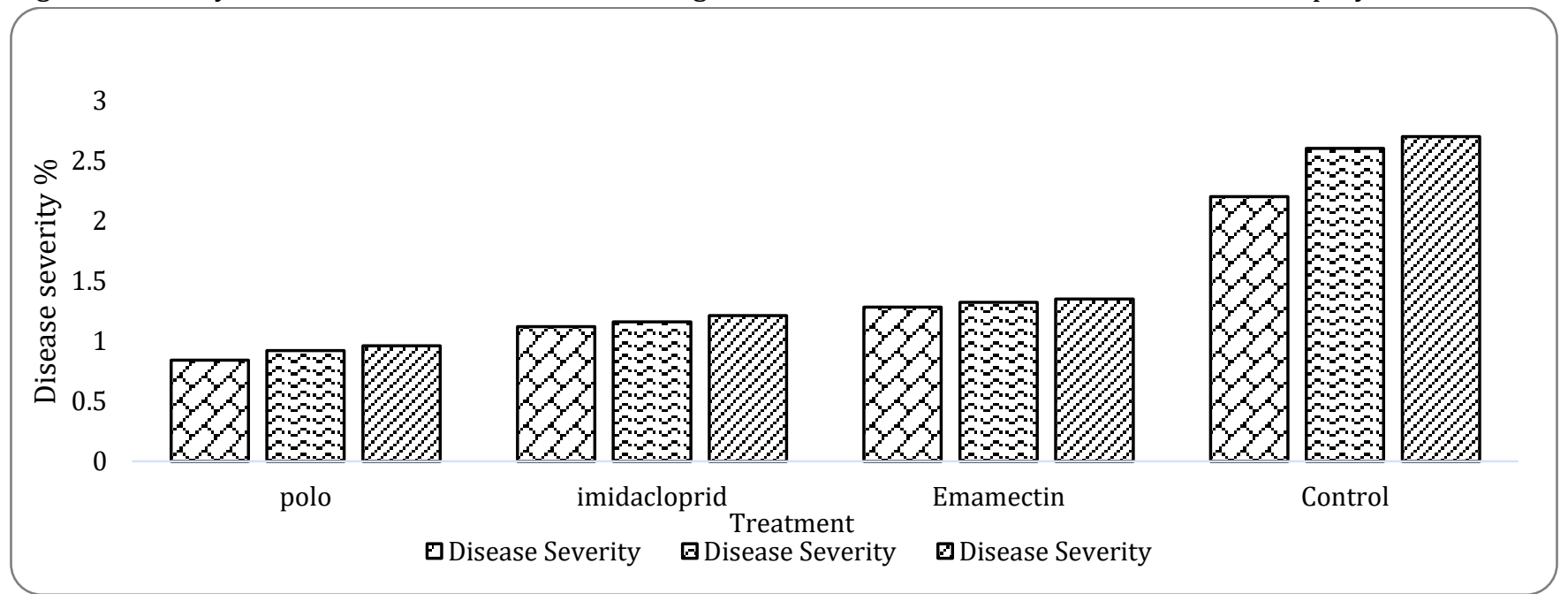

Figure 4. Efficacy of Polo, Imidacloprid and Emamectin against chilli leaf curl disease severity at three weekly intervals in comparison to control. 
Pak. J. Phytopathol., Vol. 29 (01) 2017. 17-22

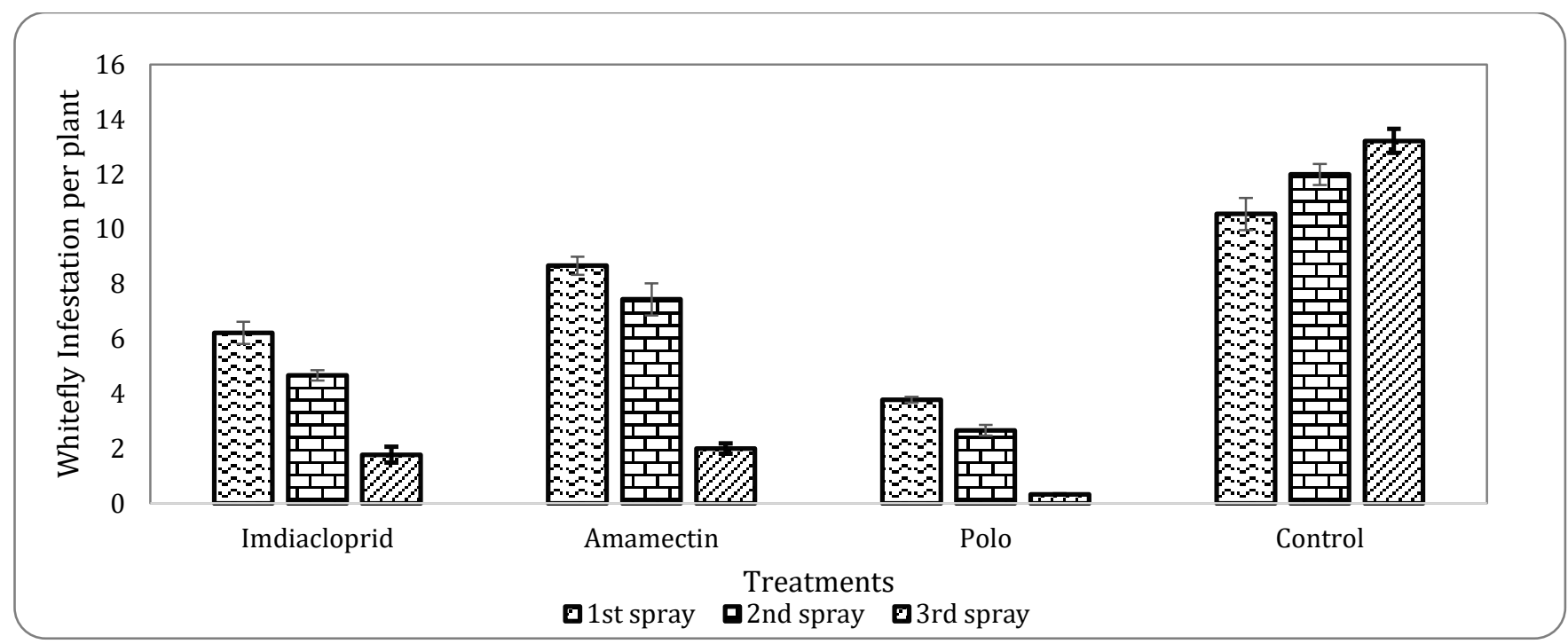

Figure 5.Efficacy of different insecticides on whitefly population control sprayed at weekly intervals

After screening, we checked the effect of different insecticides for disease management and whitefly control. For the management of chilli leaf curl disease and whitefly population, different insecticides were evaluated. Out of all insecticides used, Polo gave best results with minimum disease incidence as compared to other treatments (Fig. 3). At first spray disease incidence in Polo (21.45), Imidacloprid (32.45), Emamectin (42.55) and control (85.24) but in $2^{\text {nd }}$ spray Polo (22.66), Imidacloprid (33.65), Emamectin (42.9) and control was (87.33). At $3^{\text {rd }}$ spray Polo (23.05), Imidacloprid (33.9), Emamectin (43.88) and control (89) gave good control of whitefly population whereas disease increased in untreated control (T4). In case of disease severity, overall Polo gave best result (Fig: 4) that at $1^{\text {st }}$ spray, disease severity was less but slightly increased at $2^{\text {nd }}$ and $3^{\text {rd }}$ sprays. While in case of whitefly population, polo also gave best results for controlling whitefly population as compared to other. Minimum whitefly population was observed in case of Polo treated plots whereas maximum whitefly population was found in untreated control (Fig. 5). The results of this study showed that insecticides offer a better control of ChiLCV if timely applied before the start of infection in the season. Polo should be used when the plants are young in order to protect them from whitefly infestation. The results were supported by the findings of Talukder et al., (2012) who evaluated the efficacy of different chemicals and barrier crops for the management of chilli leaf curl disease. They evaluated different chemicals over three consecutive years including Admire (0.05\%), Omite (0.1\%), Furadan 5G $(30 \mathrm{~kg} / \mathrm{ha})$, milk $(10 \%)$ and barrier of foxtail millet one row after one row. Barrier of foxtail millet one row after one row gave maximum disease control in comparison to control and gave highest yields followed by Admire and Furadan whereas untreated control had highest percentage of diseased plants. The results were similar with the results of Singh et al., (1978) who performed experiments for controlling Chilli leaf curl virus and whitefly vector through different insecticides. The study revealed that one soil application of Carbofuran @ $1.5 \mathrm{~kg}$ a.i $/$ ha or Disulfotan@1.5 kg /ha or four sprays of power oil $(1 \%)$ at ten days intervals effectively controlled whitefly and reduced incidence of leaf curl disease. An increase in yield was also observed in treated versus untreated plants. Other insecticides including Dimethoate $(0.05 \%)$ and Oxydemeton methyl $(0.05 \%)$ were also effective in controlling the disease. The results of the study show that Polo, Emamectin and Imidacloprid are effective in the management of leaf curl in chilli under field conditions. Timely application of these insecticides can be useful in controlling the disease and increase crop yields.

\section{REFERENCES}

Agriculture Statistics of Pakistan 2010-11. Pakistan Bureau of Statistics, Government of Pakistan.

Ashfaq, M., M.A. Khan, S.M. Mughal, N. Javed, T. Mukhtar and M. Bashir. 2007. Evaluation of Urdbean germplasm for resistance against 
Urdbean leaf crinkle virus. Pak. J. Bot., 39(6): 2103-2111.

Bosland P.W. and E.J. Votava. 2000. Peppers: Vegetable and Spice Capsicums. CABI Publishing, CAB International, Wallingford.

Dorantes, L., R. Colmenero, R.H. Hernandez, L. Mota, M.E. Jaramillo, E. Fernandez, and C. Solano. 2000. Inhibition of growth of some foodborne pathogenic bacteria by capsicum annum extracts. Int. J. Food Microbiol. 57(1): 125-128.

Fauquet C.M. and J. Stanley. 2003. Geminivirus classification and nomenclature: progress and problems. Ann. Appl. Biol. 142, 165-189.

Gomez, P., A.R. Hernandez, B. Moury, M. Aranda. 2009. Genetic resistance for the sustainable control of plant virus diseases, breeding, mechanisms and durability. Eur. J. Pl. Pathol. 125 (1): 1-22.

Hameed. S., H. Shah, H. Ali and S. Khalid. 1995. Prevalence of chilli viruses in Pakistan. Fifth National Congress of Plant Sciences, 1995, March 28-30. NARC, Islamabad.

Iqbal S., M. Ashfaq, H. Shah, M.I. Haq and Aziz-Ud-Din. 2012. Prevalence and distribution of Cucumber mosaic cucumovirus (CMV) in major chilli growing areas of Pakistan. Pak. J. Bot. 44(5): 1749-1754.

Kraft K.H., C.H. Brown, G.P. Nabhan, E. Leudeling, J.D.J. Luna Ruiz, G.C.D. Eeckenbrugge, R.J. Hijmans, and P. Gepts. 2014. Multiple lines of evidence for the origin of domesticated chilli pepper, capsicum annum, in Mexico. PNAS. 111(17): 6165-6170.

Kumar, S and M. Rai. 2005a. Chile in India. Vol. XXII. Chile Pepper Institute Newsletter, pp. 1-3.

Kumar S., S. Kumar, M. Singh, A. K. Singh and M. Rai. 2006b. Identification of host plant resistance to pepper leaf curl virus in chilli (Capsicum species). Scientia Horticulturae 110:359-361.

Meghvansi, M.K., S. Siddiqui, H. Khan, V.K. Gupta, M.G. Vairale, H. K. Gogo and L. Singh. 2010. Naga chilli: a potential source of capsaicinoids with broad-spectrum ethnopharmacological applications. J. Ethnopharmacol. 132: 1-14.

Olmstead., G. Richard, Bohs, Lynn, Migid, Hala Abdel, S. Valentin, Eugenio, Garcia, F. Vicente, \& Collier, M. Sarah. 2008. A molecular phylogeny of the Solanaceae. Taxon, 57(4): 1159-1181.

Pawar ,S.S., N.V. Bharude, S.S. Sonone, R.S. Deshmukh, A.K. Raut, and A.R. Umarkar. 2011. Chillies as food, spice and medicine, a perspective. Int. J. Pharm. Biologic. Sci. 1(3): 311-318.

Peter K.V, 1999. Making of global leader in the production of spices. The Hindu Survey of India Agriculture. 81-84.

Senanayake, D.M.J.B., B. Mandal, S. Lodha and A.Verma. 2006a. First report of chilli leaf curl virus affecting chilli in India. New Dis Reports. 13(27).

Senanayake D.M.J.B., A. Varma, B. Mandal. 2012b. Virus-vector relationships, host range, detection and sequence comparison of chilli leaf curl virus associated with an epidemic of leaf curl disease of chilli in Jodhpur, India. Phytopathol. 160 (3): 146-155.

Shah, H., and S. Khalid. 2001. Screening of exotic pepper lines against local isolate of Chilli veinal mottle potyvirus. J.Bologic.Sci.1(11):1078-1080.

Singh, S.J., K.S. Sastry, and K.S.M. Sastry. 1979. Efficacy of different insecticides and oils in the control of leaf curl virus disease of chillies. J. Pl. Dis. and Prot. 86(5): 253-256.

Stenger D.C., J.E. Duffus, B. Villalon. 1990. Biological and genomic properties of a Gemini virus isolated from pepper. Phytopathol. 80: 704709.

Talukder, M.M.R., M. Riazzudin, E. Mahmud, M.S. Uddin and, M.S.I. Khan. 2012. Management of leaf curl disease of chilli by using chemicals and barrier crop. Int. J. Sustain. Crop Prod. 7(2): 9-11. 